\title{
Increase in Jugular Venous Pressure
}

National Cancer Institute

\section{Source}

National Cancer Institute. Increase in Jugular Venous Pressure. NCI Thesaurus. Code

C119206.

A finding of an increase in the jugular venous pressure, as measured by the height of the mean jugular venous waveform above the right atrium. 